\title{
Modelo de Controle Gerencial para Gestão de Projetos de Tecnologia de Informação
}

\author{
Prof. Dr. Raimundo Nonato Sousa Silva ${ }^{1}$ \\ Faculdades Ibmec - Rio de Janeiro \\ nonato@,ibmecrj.br \\ Marco Aurélio da Conceição Ribeiro², \\ Faculdades Ibmec - Rio de Janeiro \\ marcoribe@ig.com.br
}

\begin{abstract}
Resumo
Os investimentos efetuados em tecnologia da informação tem sido objeto de críticas quase sempre pautadas pela baixa relação de eficiência dos projetos e os recursos consumidos para implementálos. Como solução para esse impasse, a construção de portfólio de projetos tem sido uma prática adotada com vistas a garantir o retorno dos investimentos aplicados em tecnologia da informação. Através da gestão de portfólio de projetos a organização pode distribuir melhor os recursos quase sempre limitados e escassos, investindo em projetos que irão gerar o maior valor ao negócio. Em face disso, este artigo tem por objetivo fazer uma descrição dos principais aspectos da gestão de portfólio de projetos de tecnologia da informação bem como fornecer uma proposta de modelo de acompanhamento e controle desses projetos usando como base a estrutura de sistemas de controle gerencial proposto Flamholtz [5].
\end{abstract}

Palavras-chave: Tecnologia da Informação, Sistema de Controle Gerencial, Gestão de Projeto.

\begin{abstract}
The investments made on information technology have been target of critics and almost always based on the low correlation between project efficiency and the resources used to implement them. As a solution to this dilemma, the construction of project portfolios has been a practice adopted in sight to assure the return of the investments applied on information technology. Through project portfolio management the organization can distribute better the almost ways limited and scarce resources, investing in projects that will generate greater value to the business. In face of the above, this article has the objective of describing the main aspects of information technology projects portfolio management as well as supplying a proposal of a model of tracking and control of these projects based on the structure of management control system proposed by Flamholtz [5].
\end{abstract}

Keywords: Information Technology, Management Control Systems, Project Management.

\section{Introdução}

As empresas vêm buscando diversas fórmulas para se obter sucesso em seus negócios, o que pode ser percebido através de ações estratégicas que visam buscar: eficiência para competir dentro de seu mercado, vantagens competitivas sobre as demais correntes, respostas rápidas às mudanças no ambiente de negócio, dentre outras ações para se alcançar sucesso e se ter maior lucratividade. Essas questões fazem parte de uma estratégia competitiva definida por cada empresa, como conceituação apresentada por Porter [20] para estratégia competitiva: "estratégia competitiva significa escolher deliberadamente um conjunto de atividades que agregam a empresa um mix único de valor". 
A estratégia definida pela organização é descrita em um planejamento estratégico que tem como saída diversos planos de ações, estes, por conseguinte, são compostos por uma série de iniciativas que são executadas através de vários projetos. Estes projetos são os responsáveis finais pelo sucesso da estratégia da organização.

No entanto, observa-se que na maioria das organizações estes projetos, que irão implementar a estratégia, são ainda tratados de forma isolada sem que se tenha a visão e o acompanhamento integrado do conjunto de projetos e de seus resultados para o negócio. Esta situação pode ser confirmada no relato de Ron Kifer Datz [4], vicepresidente de gerenciamento de programas da DHL, de que nas últimas três empresas em que trabalhou, os vice-presidentes de cada área de negócio não possuíam nenhum processo definido para revisão das propostas de projetos e, na maioria das vezes, eles tentavam executar mais projetos do que tinham capacidade para fazer e não se tinha visão do conjunto de ações que estavam sendo feitas pela empresa.

Benko e McFarlan [1] demonstram em seus estudos que a grande maioria das empresas não possui uma estratégia para gerenciar seus projetos de forma a gerar o maior valor possível e mapear a efetiva ligação entre estes valores e as necessidades da organização. Os autores propõem que os projetos sejam gerenciados em portfólios, devendo se reconhecer o relacionamento entre cada um dos projetos e o alinhamento destes projetos com a estratégia corporativa.

Este cenário de falta de visão estratégica na gestão do pool de projetos de uma empresa pode ser fortalecido pelas constatações feitas em estudos realizados por Wheil e Broadbent [22]; Benko e McFarlan [1], Kendall e Rollins, [14] de que em muitas empresas o foco principal da execução de projetos ainda é na eficiência operacional, isto é, preocupa-se em se ter o trabalho feito conforme especificado. Esta abordagem enfatiza a eficiência do trabalho, em relação ao tempo e prazo gastos na execução dos projetos. Fazendo uma correlação com Porter [20], percebe-se que esta abordagem é focada na efetividade operacional e não no posicionamento estratégico que deveria ser: pensar na contribuição do resultado de cada um dos projetos e do conjunto dos mesmos para resultado global do negócio.

Este enfoque operacional não representa necessariamente uma prática ruim, porém, conforme observado por Porter [20], o ponto principal de atenção das estratégias das empresas deve ser a busca por uma vantagem competitiva de fato que, neste caso, virá somente quando se souber demonstrar que o conjunto de projetos executados pela organização gerou o resultado previsto pelo planejamento estratégico.

\section{Revisão de Literatura}

A gestão de portfólio de tecnologia da informação tem sua base na Teoria Moderna de Portfólio (TMP), enunciada inicialmente por Harry Markowitz [17], no paper "Portfolio Selection" em que o autor descreve como gerenciar um conjunto diversificado de investimentos específicos para que se atinja um retorno ótimo a partir da avaliação do nível de risco desses investimentos, dados a performance e os objetivos almejados pelo investidor.

McFarlan [16] aplicou os conceitos da TMP para a gestão de projetos de desenvolvimento de sistemas de informação, sugerindo a adoção de uma abordagem de portfólio baseada na seleção e gerenciamento destes projetos com ênfase na gestão de riscos de cada um dos projetos e na carteira de projetos da organização como um todo. McFarlan propõe que os gerentes de projeto devam distribuir seus recursos de forma a mitigar os riscos de cada um dos projetos, bem como, gerenciar os níveis de risco atribuídos ao portfólio de projeto de sistemas de informação.

Em meados dos anos 90, o tema portfólio de tecnologia da informação ganhou maior destaque e atenção por parte das empresas, praticantes e estudiosos. Em 1994, o governo americano através do GAO (General Accounting Office), reconhecendo a importância do tema na administração pública, lança um relatório intitulado "Improving Mission Performance Through Strategic Information Management: Learning from Leading Organizations". Este relatório tem por objetivo identificar as práticas de sucesso, utilizadas por empresas do setor privado e público, na gestão de TI que demonstraram gerar uma melhoria de performance e bons resultados aos negócios de suas respectivas empresas.

Além disto, outra necessidade latente no estudo do GAO era poder compartilhar conhecimentos adquiridos com os executivos do governo federal, de tal forma a minizar os problemas do mau aproveitamento do investimento público em TI e diminuir o gap da expectativa do público em relação à performance das agências. Um dos pontos mais destacados no relatório é a 
identificação da necessidade de se ter um portfólio de projetos de tecnologia da informação que melhore a tomada de decisões de investimentos em TI, permitindo o maior alinhamento ao planejamento estratégico estabelecido pelo governo.

Desde então, o GAO e outros órgãos do governo americano, tais como, Office of Management of Budget (OMB) e o Office of the Auditor General of British Columbia, vêm divulgando diversos outros relatórios com propostas de utilização de melhores práticas e técnicas de gestão do portfólio de tecnologia da informação. Em 2004, o último relatório de expressão lança pelo GAO é o “ Information Technology Investment Management - A Framework for Assessing and Improving Process Maturity" que descreve as fases, estágios de maturidade, para implementação das práticas de gestão de investimentos de tecnologia da informação.

Wheil e Broadbent [22] são alguns dos autores que vém destacando a importância do papel da gestão do portfólio de TI no alinhamento dos investimentos em tecnologia da informação e a estratégia de negócio da empresa. Dissertando sobre o assunto, os autores lançaram em 1998 o livro "Leveraging the new infrastructure: how market leaders capitalize on information technology". Baseados em oito anos de pesquisas realizadas em mais de 75 empresas, os autores abrem uma discussão sobre quais as melhores práticas e estruturas de portfólio de tecnologia da informação que venham propiciar o melhor alinhamento dos objetivos estratégicos das empresas e os investimentos disponibilizados para tecnologia da informação, de tal forma a atingir o maior desempenho possível, permitindo-se também a avaliação do valor agregado ao negócio. Segundo os autores, o completo alinhamento nunca poderá ser atingido, pois as demandas do negócio, atividades competitivas, necessidades de gerenciamento $\mathrm{e}$ as escolhas tecnológicas estão constantemente mudando e as empresas, frequentemente, levam certo tempo para construírem ou modificarem seu portfólio de tecnologia da informação. Weill e Broadbent [22] propõem a estruturação do portfólio de TI com base em quatro objetivos gerenciais (ver fig.1), que podem gerar valor ao negócio através de duas formas: suporte ao sucesso da implementação das estratégias atuais e uso da tecnologia para habilitar novas estratégias.

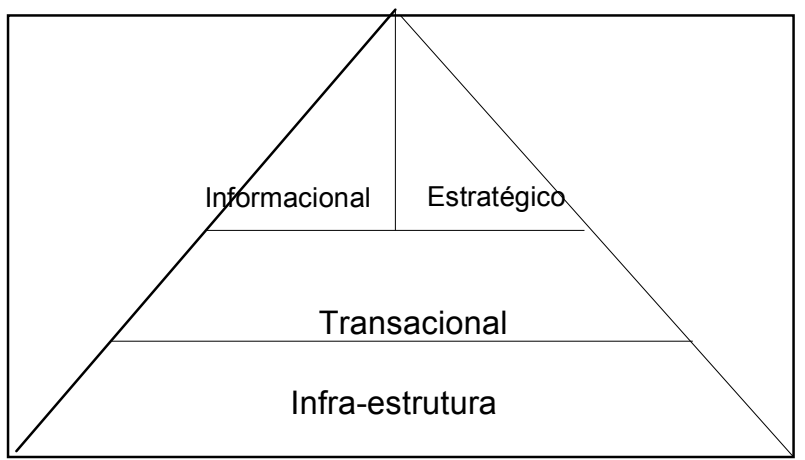

Fig. 1 - Fonte: Leveraging the new infrastructure: how market leaders capitalize on information technology Wheil and Broadbent [22]

. Infra-estrutura - é a base do portfólio de TI, representa o alicerce necessário para o desenvolvimento de todos os serviços compartilhados oferecidos pela área de tecnologia da informação.

- Transacional - representa o conjunto de aplicações de TI que suportam a operação do negócio da empresa. Juntamente com os serviços de infra-estrutura são pré-requisitos para o desenvolvimento dos níveis superiores, informacional e estratégico.

- Informacional - composto pelas tecnologias capazes de fornecer informações gerenciais e de controle necessárias nos processos de planejamento, tomada de decisão, comunicação, contabilização, dentre outros processos gerencias da organização.

- Estratégico - representam as tecnologias utilizadas com o objetivo de se obter uma vantagem competitiva ou melhorar o posicionamento da empresa no mercado.

Benko and McFarlan [1] no livro "Conecting the Dots: Aligining the projects with Objectives in Unpredictable Times" debatem a importância da gestão de portfólio de TI no alinhamento estratégico das empresas e apresentam conceitos e práticas de como determinar o quão alinhado à estratégia está a organização e reduzir os riscos do portfólio melhorando-se a eficiência do negócio, dentre outras sugestões.

Dois dos principais institutos de pesquisas e análises da indústria de tecnologia da informação, Gartner e Meta Group, têm realizado, nos últimos anos, diversos estudos, análises e conferências sobre o tema gestão de portfólio de TI, apontando 
o assunto como uma das principais formas dos diretores e executivos de TI planejarem o investimento em tecnologia, de forma a alinhar suas ações as necessidades de negócio, além disto, é um processo primordial para se demonstrar aos executivos seniores das organizações o efetivo retorno sobre o investimento realizado em tecnologia da informação e como a tecnologia está sendo utilizada na implementação da estratégia corporativa. Segundo resultados de pesquisas pelo instituto Meta Group [18], as empresas tem apresentado as seguintes falhas:

- $84 \%$ da empresas não fazem estudos de casos para todos os projetos ou fazem somente para alguns poucos projetos chaves;

$83 \%$ das empresas são incapazes de ajustar ou alinhar seus orçamentos as necessidades de negócio mais de uma ou duas vezes ao ano;

$89 \%$ das organizações estão "voando as escuras", somente possuem métricas financeiras, pode-se ser comparar esta situação a um avião sendo monitorado apenas pelo consumo de combustível.

\subsection{Fundamentos da Gestão de Portfólio de TI}

O objetivo principal da gestão de portfólio é direcionar a organização para obtenção do maior valor ao negócio a partir dos investimentos realizados por ela sobre os ativos existentes ou em novos ativos segundo objetivos estratégicos previamente estabelecidos. Como em qualquer portfólio cada ativo ou investimento possui objetivos diferentes, isto é, cada um tem riscos, custos-benefício, necessidades de recursos, dentre outras características próprias que devem ser analisadas separadamente e em conjunto como um todo, considerando-se o impacto da interdependência de cada investimento ou ativo nos objetivos estabelecidos.

Os ativos, no caso específico de portfólio de TI, nos quais ocorrem investimentos são das seguintes categorias:

Infra-estrutura: redes de computadores, dispositivos de pontos de vendas, estações de trabalhos, scanners, rede de telecomunicações, banco de dados, softwares, dentre outros itens.
- $\quad$ Sistemas: de suporte a operação, ERP, sistemas de apoio a decisão, sistemas de informação gerencial, dentre outros.

- Serviços: de manutenção, suporte, desenvolvimento de aplicações, treinamentos, dentre outros que podem ser realizados de forma centralizado, descentralizado, distribuídos, ou terceirizados.

$\begin{array}{ccc}\text { • } & \text { Humanos: } & \text { contratações, } \\ \text { capacitação, } & \text { programas de incentivos / }\end{array}$ participação dentre outros.

- Gestão: refere-se aos investimentos realizados para implantação de melhores práticas em processos de gestão (governança) e operação ou frameworks desenvolvidos por instituições especialistas em práticas de TI.

Outra característica distinta do portfólio de TI, é que o mesmo é composto por investimentos em manutenção da operação e outros investimentos destinados à aquisição e implantação de novos ativos relacionados à estratégia da organização. Os novos ativos, bem como os investimentos na manutenção da operação, serão tratados através da execução de projetos que dada suas características próprias, tais como, prazo, custo, recursos envolvidos e competências necessárias, qualidade, valor potencial e valor realizado, podem ser tratados em um portfólio específico.

Para uma gestão de portfólio eficiente são necessários processos formais e estruturados, suportados por uma estrutura de governança bem consistente, além de uma ferramenta para administração de inventário de ativos de TI conforme Weill e Broadbent [22]; CIO Council, [2]; Meta Group, [18]; Gaddie [6]. A gestão de portfólio envolve a identificação, seleção, priorização, orçamento / financiamento, monitoramento e avaliação do mix de projetos que deve ocorrer de forma contínua dentro da organização.

Um dos elementos que devem ser estabelecidos logo de início na implementação de processos de gestão de portfólio é a adoção de um inventário de ativos de TI centralizado conforme orientam Weill e Broadbent [22]; CIO Council, [2]; Prahalad e Krishnan [19]; Gaddie [6]; Jeffery e Leliveld [13]. O inventário de TI deve conter os principais indicadores para controle e avaliação de cada ativo, bem como o da carteira de projetos como um todo: efetividade em atingir as necessidades de negócio, potencial de 
crescimento, ROI, custo de operação e manutenção, riscos, interdependência, dentre outros indicadores mencionados em GAO [8].

Governança em TI é o processo que envolve a autoridade e responsabilidade na tomada de decisão que garanta que os indivíduos tenham um comportamento adequado e desejado no uso da tecnologia da informação e requer uma linha de ação clara para seleção dos decisores e grupo de decisores que formarão os comitês de governança mencionados em Gerrard [10] e Dallas [3]. O processo de governança necessário à gestão do portfólio de TI deve ser parte da governança corporativa de TI e também estabelecer o direcionamento para o alinhamento do portfólio de TI, estabelecer padrões, critérios e princípios a serem adotados na gestão e tomadas de decisão que envolva o portfólio e definir e participação dos decisores nos processos de seleção, priorização e acompanhamento dos investimentos em TI.

Os processos de seleção e priorização de investimentos em ativos de TI são partes essenciais na determinação do quão alinhada estará a tecnologia da informação à estratégia corporativa, pois a seleção do conjunto certo de projetos que por suas características irão gerar o maior valor para organização é o primeiro passo para direção dos objetivos estratégicos corporativos definidos. Seguido a esta seleção, é primordial a priorização destes investimentos, dado as limitações de recursos, humanos, físicos e financeiros, inerentes em maior ou menor escala a cada organização.

A implementação dos processos de seleção e priorização dos investimentos requer algumas premissas básicas: definição dos grupos de decisores (comitês) ou decisor (é menos comum ter somente um responsável pela decisão), estabelecimento de critérios e valores (pesos) a serem utilizados por cada um dos processos, definição de uma metodologia para apoio a tomada de decisão que pode ser oriunda de um dos métodos com base teórica existentes: AHP, teoria multi-atributo, dentre outros ou a partir de métodos específicos criados por cada empresa, como o modelo utilizado pela Sun baseado na definição de critérios quantitativos e qualitativos para criação e manutenção de seu portfólio de Internet conforme consta em Tjan [2001] e a construção de casos de negócios para cada um dos investimentos demonstrando-se: os riscos, custobenefício, justificativa do investimento, incluindo as metas estratégicas a serem atingidas, estimativa inicial de investimento e retorno previsto (valor potencial do investimento).

O processo de orçamento é outro elemento de destaque na gestão do portfólio, pois precisa ser justificado segundo as regras de investimento e metas estratégicas da empresa contando na elaboração com a participação dos respectivos executivos das áreas de negócio e sendo aprovado pelo comitê da alta direção. Além disto, o orçamento deve estar integrado aos processos de seleção e priorização, devendo o mesmo ser um item passivo de revisões e avaliações periódicas regulares pelo comitê de governança de TI.

Os últimos elementos de destaque da gestão de portfólio são o controle e avaliação da carteira. Estes elementos envolvem as atividades monitoramento do desempenho da carteira de investimentos e ativos, direcionamento das melhorias contínuas dos ativos existentes e desenvolvimento de ações corretivas para ajustes e redirecionamento do portfólio conforme consta no Meta Group [18].

\section{Modelo de Gestão de Portfólio de TI Baseado em Sistema de Controle Gerencial}

Conforme mencionado antes, este artigo pretende apresentar um modelo de gestão de portfólio de TI baseado na estrutura de controle proposta por Flamholtz [5]. Segundo o autor, um sistema de controle organizacional pode ser definido como um conjunto de mecanismos, processos e técnicas, que são projetados para aumentar a probabilidade das pessoas agirem adequadamente na direção dos objetivos organizacionais (congruência de objetivos). Além disto, um sistema de controle deve executar quatro funções:

- Motivar as pessoas a terem foco nas metas organizacionais

- Gerar a integração dos esforços das pessoas da organização

- Permitir aos gerentes executarem suas operações diárias e acompanharem dos resultados das ações e decisões tomadas

- Facilitar a implementação das ações do planejamento estratégico

Segundo a definição e as funções propostas por Flamholtz [5] para um sistema de controle gerencial, os conceitos de gestão de portfólio de TI enquadram-se nos mesmos, podendo-se projetar um sistema de gestão de portfólio, 
segundo as regras estabelecidas pelo autor. $\mathrm{O}$ modelo proposto por Flamholtz [5] para um sistema central de controle prevê cinco componentes básicos:

- Planejamento

- Operação

- Mensuração

- Avaliação

- Premiação

A figura 3, a seguir apresenta os cinco componentes correlacionados.

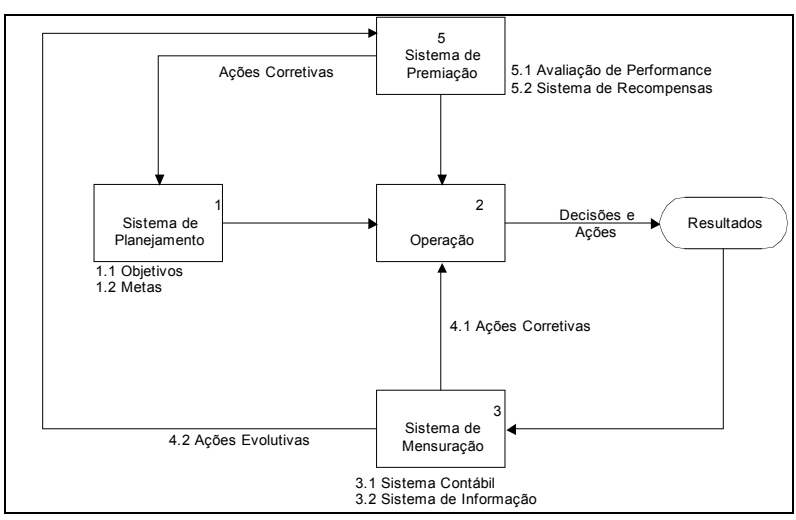

Fig.2 Fonte: Effective Organizational Control: A Framework, Applications, and Implications - Eric Flamholtz [5].

No modelo de gestão de portfólio de TI proposto neste estudo foi adotado a configuração dos elementos do sistema do terceiro nível de controle proposto por Flamholtz [1996], conforme figura 3 abaixo:

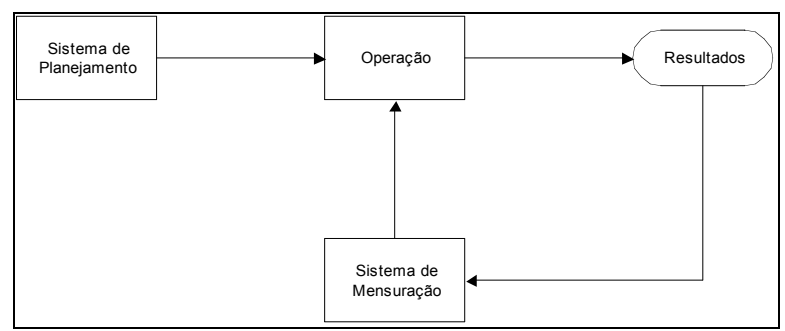

Fig.3 Fonte: Effective Organizational Control: A Framework, Applications, and Implications - Eric Flamholtz [5].

Esta configuração foi adotada, pois contempla as funções básicas de planejamento, operação e mensuração, para a implantação inicial de um sistema de gestão de portfólio de TI em organizações que se encontrem na fase inicial de adoção destas práticas de gestão em TI. O objetivo do modelo proposto neste estudo é estabelecer uma orientação inicial para áreas de tecnologia da informação das empresas que queiram implantar processos de gestão de portfólio de TI, pois um processo completo de implantação de gestão de portfólio, tal como um sistema de controle que sugere Flamholtz [5], dependerá de uma análise da estrutura e cultura organizacional de cada empresa.

Desse modo, o modelo de gestão de portfólio de TI proposto basea-se na estrutura de sistema de controle organizacional de Flamholtz [5] e contempla os elementos mínimos para implementação inicial de processo eficiente de gestão de portfólio de TI. Segue as descrições dos elementos do sistema de controle:

\subsection{Planejamento}

Esta etapa deve ocorrer, geralmente, em períodos anuais e ter revisões eventuais, segundo a necessidade de cada organização. O planejamento deverá ser efetuado tendo como base as seguintes etapas:

\subsubsection{Estabelecer Governança}

Esta etapa visa definir as responsabilidades e autoridades nas tomadas de decisões dos processos de gestão, de forma orientada as metas a serem atingidas. Além disto, deverão ser consideradas a estrutura e a cultura da organização e devem ser estabelecidos as atividades, procedimentos e papéis envolvidos em cada um dos processos que exija uma tomada de decisão. Esta etapa deve esclarecer, segundo informa Gerrard [10], questões como::

a. Quando uma decisão individual é necessária? b. Quando as decisões devem ser
compartilhadas?

c. Que tipos de informações são requeridas para a tomada de decisão?

d. Quais comitês consultivos devem ser formados para suportar os decisores?

e. Quais as equipes necessárias para apoiar o processo de gestão de portfólio?

\subsubsection{Estabelecer categorias do portfólio}

Assim como qualquer carteira de investimentos financeira, a carteira de investimentos de TI é composta de ativos e projetos com diferentes riscos, benefícios e retornos financeiros. Todavia, existem diferentes grupos de interesse 
(investidores) dentro da organização com diferentes objetivos e expectativas. Todas essas características precisam ser analisadas para o estabelecimento da melhor categorização do portfólio de TI.

\subsubsection{Estabelecer critérios de seleção e priorização}

Para o estabelecimento dos critérios de seleção e priorização é necessário inicialmente modelar o problema de decisão, isto é, dado as categorias do portfólio e metas a serem atingidas devem ser estabelecidos os critérios, seus respectivos pesos e a escala de medição, segundo a meta a ser atingida. Algumas técnicas, tais como: brainstorm, matriz de prioridade, diagrama de espinha de peixe, árvores de decisão, mapas cognitivos, dentre outras técnicas constantes em Gomes, Gomes e Almeida [11] podem ser utilizadas como auxílio a execução desta etapa. Existem também métodos específicos para definição de sistemas de apoio a tomada de decisão gerencial que podem também ser utilizados, sendo os mais conhecidos: teoria da utilidade multi-atributo, AHP, métodos electre, dentre outros constantes em Gomes, Araya, Carignano [12].

\subsubsection{Estabelecer critérios de avaliação}

O estabelecimento dos critérios de avaliação é de extrema importância para demonstração da eficácia do processo de gestão de portfólio e o atingimento do alinhamento estratégico desejado pela empresa. Novos critérios de avaliação podem ser definidos nesta etapa ou podem ser utilizados modelos de controles desenvolvidos para acompanhar as ações relacionadas ao planejamento estratégico da organização, como por exemplo, o balanced scorecard de Kaplan e Norton [15].eventualmente adotado pela empresa. Uma boa definição dos critérios de avaliação permitirá à organização o acompanhamento do desempenho das metas estratégicas de curto e longo prazo da carteira de investimento de TI.

\subsubsection{Definir metodologia para gestão de portfólio}

Compreende na definição da estrutura de todos os processos que irão garantir a funcionalidade e operação da gestão de portfólio de TI. Devem ser estabelecidos as entradas, saídas, procedimentos, ferramentas, técnicas, requisitos e periodicidade para a execução, responsabilidades e papéis envolvidos em cada um dos processos. O objetivo da metodologia é permitir o compartilhamento de uma visão comum da estrutura de gestão, facilitando o entendimento e a comunicação entre todos os envolvidos com a gestão de portfólio.

\subsubsection{Definir ferramentas de apoio à gestão}

Consiste na determinação e criação da estrutura do repositório central, bem como os relatórios de acompanhamento e gerenciais que irão suportar a operação da gestão de portfólio.

\subsection{Operação}

Representa o processamento contínuo das atividades de gestão do portfólio e é composto das seguintes etapas:

\subsubsection{Iniciação}

Representa os processos que devem ser executados com uma periodicidade maior do que a fase seguinte de monitoramento. Em geral, esta fase é executada em ciclos, trimestrais, quadrimestrais ou no máximo semestrais. Esta etapa visa garantir que a entrada de novos investimentos esteja alinhada a estratégia da organização. Esta fase é composta de:

\section{- Justificar investimento}

Consiste na construção de casos de negócio que devem contemplar: objetivo de negócio, estudo de viabilidade, riscos, benefícios, implicações, retorno sobre o investimento e estimativas inicias de prazo, custo e recursos.

\section{- Definir orçamento por categoria}

Estabelecer o montante a ser investido em cada uma das categorias do portfólio, considerando-se a contribuição de cada uma das categorias para o atingimento das metas estratégicas.

\section{- Avaliar portfólio existente}

Com exceção das empresas start-up, que ainda estão em fase de formação, as demais empresas já possuem uma série de ativos e projetos em andamento que devem estar cadastrados em um repositório central permitindo-se a análise prévia do portfólio.

\section{- Selecionar investimentos}

Consiste na escolha do melhor mix de investimentos que irão constituir o portfólio de TI 
de forma a preencher as necessidades de.zegðcio garantindo o maior alinhamento à estratégia da organização. Esta etapa também pode utilizar os mesmos métodos de sistemas de apoio à tomada de decisão gerencial que os adotados na etapa de definição dos critérios de seleção e priorização.

\section{- Priorizar investimentos selecionados}

Após a escolha do melhor mix de investimentos, é necessário definir a melhor ordem de execução para os investimentos, dado as restrições de recursos financeiros, materiais e humanos existentes, expectativas de tempo e valor do retorno sobre o investimento e objetivos de negócio a serem atingidos. $\mathrm{Na}$ priorização também podem ser usados os métodos de sistemas de apoio à tomada de decisão.

\section{- Definir alocação de recursos}

Última etapa da fase de iniciação, tendo como objetivo a otimização da distribuição dos recursos necessários ao desenvolvimento de cada um dos projetos, dada as características de competências e disponibilidades de cada um dos recursos exigidas pelos projetos. Também podem ser utilizados os mesmos métodos de sistemas de apoio à tomada de decisão para otimização da alocação de recursos.

\subsubsection{Monitoramento}

Consiste na monitoração do andamento do portfólio de forma a garantir a coleta de informações, o acompanhamento da operação dos processos de gestão de portfólio e o controle das mudanças nos investimentos solicitadas. Esta fase é composta das seguintes ações:

\section{-Coletar informação}

Visa garantir que as informações pertinentes a investimentos estejam sendo realizadas no repositório central e os relatórios de acompanhamento e gerenciais estejam sendo gerados.

\section{- Acompanhar andamento do portfólio}

Consiste no acompanhamento da execução dos projetos de investimentos, verificando-se principalmente os seguintes aspectos:

a) Fase do ciclo de vida que o projeto se encontra;

b) Investimentos já realizados e a realizar;

c) Trabalho já realizado;

d) Necessidades de recursos; e) Tempo gasto na execução e tempo restante para finalização do projeto.

\section{- Controlar mudanças}

Visa controlar as solicitações de inclusão de novos requisitos ou alterações em função de mudanças no ambiente de negócios. A toda solicitação deve-se fazer uma análise prévia de seus impactos técnicos e de negócio no resultado final do investimento. Esta etapa também deve estar bem sincronizada aos procedimentos da governança de gestão de portfólio visando garantir que a solicitação passe pelo correto nível de aprovação.

\subsection{Mensuração}

Representa o processamento contínuo de avaliação das atividades de gestão do portfólio bem como corrigir e gerar ações de melhorias. Esta etapa é composta das seguintes ações:

\section{- Avaliar performance}

A partir das informações coletada dos indicadores de desempenho do negócio e do desempenho da carteira de investimentos, armazenadas no repositório central, é possível estabelecer a relação causa-efeito entre cada indicador e os objetivos e metas estratégicos da organização. Além disto, é possível gerar subsídios para a avaliação o desempenho do negócio, o que permitirá aos comitês responsáveis proporem ações necessárias para melhoria do desempenho da carteira, se necessário.

\section{- Gerar ações corretivas}

A partir da avaliação do desempenho necessária, algumas vezes serão necessária a tomada de ações corretivas para garantir o realinhamento do portfólio à estratégia da organização.

\section{- Gerar ações evolutivas}

Outro tipo de ações que podem ser geradas a partir da análise de performance e experiências adquiridas durante a execução do processo de gestão de portfólio, são ações evolutivas que buscam introduzir melhorias ao processo de gestão de portfólio com o objetivo de superar as expectativas estabelecidas.

A figura 4, a seguir, mostra o fluxo completo de planejamento, operação e monitoração do modelo de gestão proposto. 


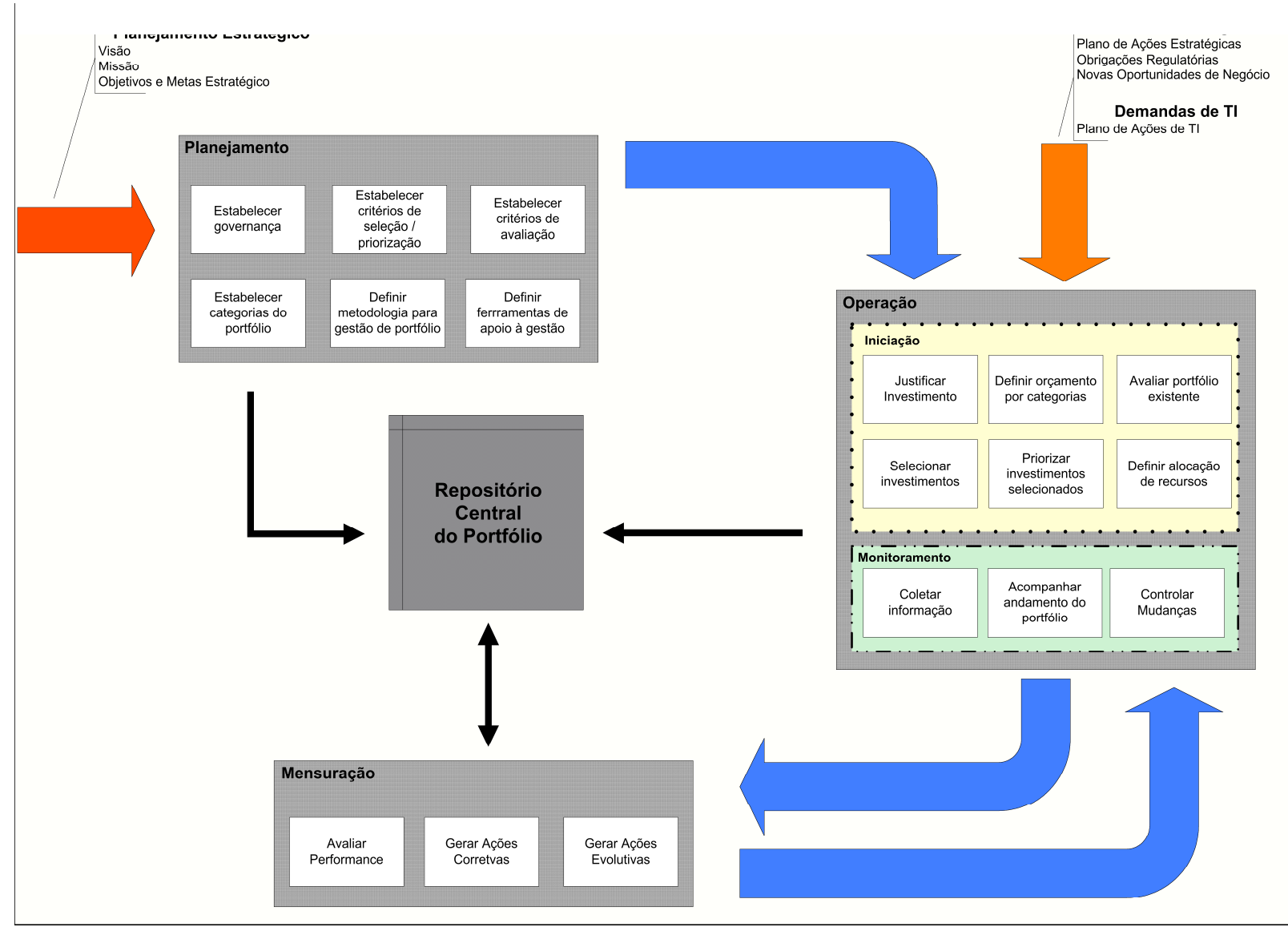

Fonte: Autores

\section{Conclusão}

Conforme apresentado, a gestão de portfólio de TI é uma das atividades de grande importância dentro da área de tecnologia, principalmente para as empresas que executam um grande número de projetos de TI anualmente. A gestão do portfólio permite a organização direcionar melhor os esforços e aplicação de recursos nas iniciativas mais alinhadas às necessidades de negócio bem como acompanhar e avaliar o desempenho de suas ações, sendo possível demonstrar aos alto executivos o valor obtido pela utilização correta das tecnologias no negócio.

Em função disso, o modelo proposto de gestão de portfólio de TI tem como objetivo ser um instrumento para as organizações que desejam adotar tais práticas gerenciais visando um alinhamento melhor da área de tecnologia com a área de gestão de negócios. Assim o modelo propõe os processos mínimos que devem ser considerados na gestão de portfólio, segundo a estrutura de sistemas de controle gerencial sugerido por Flamholtz [5].

Todavia, algumas limitações não descritas no modelo devem ser consideradas:
- Os processos contidos no modelo, principalmente o de governança do portfólio, deverão ser analisados a luz das estruturas e culturas organizacionais existentes, devendo ser necessário um projeto de gestão de mudanças que permita a implementação do modelo com os ajustes correto do impacto cultural e estrutural dentro da organização;

- O modelo tem como premissa a existência de uma fase anterior, que é o planejamento estratégico da organização, pois sem o mesmo não é possível estabelecer os parâmetros necessários ao alinhamento do portfólio à estratégia.

- Outros aspectos que influenciam diretamente na performance do portfólio e na performance do negócio, são as competências e práticas que a empresa possui no gerenciamento de projetos, pois como visto na introdução deste artigo, a eficiência operacional é um pré-requisito para o sucesso na implementação das estratégias corporativas. 


\section{Referências Bibliográficas}

[1] BENKO, Cathleen; MACFARLAN, F. W. Connecting the dots: Aligning projects with objectives in unpredictable times, Boston, Harvard Business School Press, mar 2003. ISBN 1-57851-877-6.

[2] CIO COUNCIL. A summary of first practices and lessons learnerd information technology portfolio management, mar. 2002.

[3] DALLAS, S. IT governance requires decisionmaking guidelines. Gartner Research, jan. 2003.

[4] DATZ, Ron. How to do it right. CIO Magazine, 01 mai 2003. Disponível em: $<$ http://www.cio.com/archive/050103/portfoli o.html>. Acesso em: 12 jul 2004.

[5] FLAMHOLTZ, Eric. Effective organizational control: A framework, applications, and implications. European Management Journal, Vol. 14, n.6, p. 596-611, dez 1996.

[6] GADDIE, Shelley. Enterprise programme management: Connecting strategic planning to project delivery. Journal of Facilities Management, Vol. 2, n.2, p. 117-189, set. 2003.

[7] GAO. Improving mission performance through strategic information management and technology - Learning from leading organizations: Executive Guide, mar. 1994.

[8] GAO. Measuring performance and demonstrating results of information technology investments: Executive Guide, mar. 1998.

[9] GAO. Information technology investment management - A framework for assessing and improving process maturity: Executive Guide, V. 1.1, mar. 2004.

[10] GERRARD, M. Creating an Effective IT Governance Process. Gartner Research, nov. 2003.

[11] GOMES, L.F.A.M ; GOMES, C.F.D, ALMEIDA, A.T. Tomada de decisão gerencial - Enfoque multicritério, Ed. Atlas, 2002. ISBN 85-224-3113-2.

[12] GOMES, L.F.A.M ; ARAYA, M.C.G, CARIGNANO, C. Tomada de decisões em cenários complexos, Pioneira Thomson Leaning, 2004. ISBN 85-221-0354-2.
[13] JEFFERY, Mark; LELIVELD, Ingmar. Best practices in IT portfolio management. MIT Sloan Management Review, Cambridge, Massachusetts, primavera 2004.

[14] KENDALL, Gerald I.; ROLLINS, Steve C. Advanced project portfolio management and the PMO: Multiplying ROI at warp speed, J Ross Publishing, abr 2003. ISBN 193215-902-9.

[15] KAPLAN, Robert S. e NORTON, David P. Organização Orientada para Estratégia. Editora Campus. Rio de Janeiro. 2000.

[16] MACFARLAN, F.W. Portfolio approach to information system. Harvard Business Review, p. 142-150, set/out 1981.

[17] MARKOWITZ, Harry. Portfolio Selection. The Journal of Finance, 1952.

[18] META GROUP. IT investment management: Portfolio management lessons learned: white paper. 2002.

[19] PRAHALAD, C.K.; KRISHNAN, M.S. The dynamic synchronization of strategy and information technology. MIT Sloan Management Review, Cambridge, Massachusetts, verão 2002.

[20] PORTER, Michael. What is strategy?. Harvard Business Review, Vol. 16, n.6, p. 61-78, nov/dez 1996.

[21] TJAN, Anthony. Finally, a way to put your internet portfolio in order. Harvard Business Review, p. 77-85, fev 2001.

[22] WEILL, Peter; BROADBENT, Marianne. Leveraging the new infrastructure: How market leaders capitalize on information technology , Boston, Harvard Business School Press, 1998. ISBN 0-87584-830-3.

[23] WEILL, Peter; SUBRAMANI, Mani; BROADBENT, Marianne. Building IT infrastructure for strategic agility. MIT Sloan Management Review, Cambridge, Massachusetts, outono 2002.

\section{Autores}

Raimundo Nonato Sousa Silva ${ }^{1}$ é Doutor em Engenharia de Produção pela Coppe/UFRJ (2000), Mestre em Contabilidade Gerencial pela FGV-RJ (1991). É professor da área de Controladoria e Finanças do Programa de Mestrado em Administração do IBMEC RJ. 
Marco Aurélio da Conceição Ribeiro ${ }^{2}$ é

Janeiro. É consultor em gestão de projetos.

mestrando das Faculdades Ibmec - Rio de 